\title{
"OS BRAÇOS DE DONA SEVERINA"
}

Artigo originalmente publicado em O Estado de S. Paulo, 27.07.1963,

Suplemento Literário, p. 4.

\section{LÊDO IVO}

Academia Brasileira de Letras

Rio de Janeiro, Rio de Janeiro, Brasil

\section{Apresentação de Marcelo Diego}

Universidade Federal do Rio de Janeiro

Rio de Janeiro, Rio de Janeiro, Brasil

Resumo: Em artigo de 1963, o poeta, ficcionista e também ensaísta Lêdo Ivo analisa o conto "Uns braços", de Machado de Assis, relacionando-o com outros contos do escritor, em particular, com "Missa do galo". Observa, nesse conjunto, a representação da esfera do imaginário e o papel desempenhado pelo imaginário no jogo do erotismo. Ao fim, Ivo propõe "o drama do espírito faminto de absoluto" como temática privilegiada pela ficção machadiana.

Palavras-chave: Machado e Assis; "Uns braços"; "Missa do galo"; imaginário; erotismo.

\section{"DONA SEVERINA'S ARMS"}

Abstract: In a 1963 article, poet, fictionist and essayist Lêdo Ivo analysed Machado de Assis's short story "Her Arms" and related it to other short stories written by the author, namely "Midnight Mass." In this grouping he notes the representation of the sphere of the imaginary and the role it plays in the game of eroticism. Ivo concludes by proposing "the drama of the spirit that craves the absolute" as a Machadian hobby horse.

Keywords: Machado de Assis; "Her Arms "; "Midnight Mass "; Imaginary; Eroticism. 
oi principalmente como poeta e ficcionista que Lêdo Ivo (Maceió, Alagoas, 1924 - Sevilha, Espanha, 2012) tornou-se nome incontornável da inteligência e da cultura brasileiras do século XX. Autor de obra literária vasta, em termos tanto da extensão quanto da profundidade de seus títulos, colecionou importantes prêmios no Brasil e no Exterior e foi eleito para a Academia Brasileira de Letras, em 1986. Contudo, desde que se estabeleceu, em 1943, no Rio de Janeiro, onde se formou advogado, deu início também a uma profícua colaboração com a imprensa, fazendo as vezes de jornalista e de crítico. Assim, hoje, seus ensaios assomam ao lado de seus poemas, romances, contos e crônicas como parte integrante e igualmente valiosa de sua obra, lançando luzes sobre a mesma, seu entorno e seus precursores.

Como não poderia deixar de ser, Machado de Assis é uma presença constante na reflexão crítica sobre a literatura levada a cabo por Lêdo Ivo. Hélio de Seixas Guimarães e Ieda Lebensztayn, em Escritor por escritor: Machado de Assis segundo seus pares, elencam nada menos do que vinte textos de Ivo sobre Machado, publicados na imprensa do Rio de Janeiro (na Tribuna da Imprensa, no Correio da Manhã, no Diário de Notícias, na Revista do Livro e em O Globo) e de São Paulo (n'O Estado de S. Paulo), entre 1952 e 1994, muitos deles republicados em outros periódicos e em coletâneas de ensaios do escritor alagoano (GUIMARÃES E LEBENSZTAYN, 2019, p. 190-191). Na crítica de Ivo, Machado figura não apenas como um clássico, mas como aquele que fornece o modelo do que possa ser um clássico: "Ora, para que um escritor seja clássico, é preciso antes e principalmente que seu estilo não possa ser comparado ao de outro clássico. Isto porque os clássicos são incomparáveis entre si." (IVO, 2019, p. 187)

Como discreta homenagem a Lêdo Ivo e como forma de resgatar a sua contribuição para a tradição crítica machadiana, a Machado de Assis em linha reproduz o artigo "Os braços de dona Severina", originalmente publicado no Suplemento Literário de O Estado de S. Paulo, em 27 de julho de 1963. Esse artigo forma uma espécie de díptico com outro, publicado no mesmo suplemento, do mesmo jornal, uma semana antes, no dia 20 de julho de 1963, e intitulado "Os braços de dona Conceição"; ambos os textos foram republicados no Diário de Notícias do Rio de Janeiro, um ano e meio depois, em 17 e 24 de janeiro de 1965; e finalmente incorporados ao volume Poesia observada (Rio de Janeiro: Orfeu), de 1967 (p. 21-27 e 27-32, respectivamente). Essa história de publicação revela, por um lado, que a leitura dos contos "Missa do galo" e "Uns braços", realizada em 1963, de maneira quiçá apressada, 
produzida para, na expressão machadiana, as "páginas volantes do jornalismo", o autor não apenas continuou a subscrevê-la, anos depois, como quis preservá-la para a posteridade, abrigando-a em livro. Por outro lado, essa mesma história dá dimensão da potencial penetração de tal leitura junto ao público leitor, exposto a ela em tempos e meios diversos.

A constelação machadiana observada pelo crítico nos dois artigos é a dos contos: ao centro estão "Missa do galo" (publicado originalmente em $A$ Semana, em 12 de maio de 1894; e incorporado a Páginas recolhidas, de 1899) e "Uns braços" (Gazeta de Notícias, 5 de novembro de 1885; e Várias histórias, 1896), em torno dos quais orbitam "Trio em lá menor" (Gazeta de Notícias, 20 de janeiro de 1886; Várias histórias, 1896), "Cantiga de esponsais" (A Estação, 15 de maio de 1883; Histórias sem data, 1884), "Um homem célebre" (Gazeta de Notícias, 29 de junho de 1888; Várias histórias, 1896) e "Noite de almirante" (Gazeta de Notícias, 10 de fevereiro de 1884; Histórias sem data, 1884). É digna de nota a maneira como Ivo mobiliza a ficção - ou ao menos a contística - do Bruxo do Cosme Velho de maneira integrada, "como um todo coerentemente organizado", atento às "estruturas primárias e primeiras [que] se desarticulam e rearticulam sob forma de estruturas diferentes mais complexas e mais sofisticadas" (SANTIAGO, 2020, p. 27), antecipando-se ao chamamento crítico que seria feito por Silviano Santiago em 1968.

O primeiro quadro do díptico é dedicado exclusivamente a "Missa do galo" e termina com estas palavras:

"Missa do galo", mais do que em nenhum outro ponto de sua prosa, Machado de Assis nos conduz às paragens subterrâneas da Noite. Tanto o rapazinho como dona Conceição despejam de suas almas diurnas e se entregam ao feitiço noturno, ao que, na escuridão, é silêncio, sono, sonho e rendição. Machado de Assis suspende hipnoticamente o tempo - e nesse espaço cavado na substância das horas e minutos revogados podem caber todas as castidades e volúpias. As almas e os corpos das duas personagens tanto podem manter-se fiéis às normas e preconceitos de seus espíritos solares como ouvir o apelo da Noite, esse chamamento cósmico que exclui a regra moral, elide a noção do pecado e decreta a rendição das criaturas.

E como não proceder assim, se a Noite nos espera de braços abertos? (Os braços de dona Conceição.) (IVO, 1963, p. 4)

Já o segundo quadro introduz "Uns braços" e examina os dois no interior da constelação há pouco descrita. É curiosa a percepção que o crítico tem desse conto como uma espécie de continuação, ou reescritura, da narrativa 
curta abordada no texto anterior - como um passo além que o escritor dá, na representação da esfera do imaginário e do papel desempenhado pelo imaginário no jogo do erotismo -, a despeito de "Missa do galo" ter sido composto quase uma década depois de "Uns braços". É igualmente curiosa a intuição do crítico acerca de "Missa do galo" como um conto que parece conter em si o convite à reescritura perene, à reescritura em moto-contínuo, em uma antevisão daquilo que viria a se materializar como "Missa do galo" de Machado de Assis: variações sobre o mesmo tema, reunião, lançada em 1977 (São Paulo: Summus), de contos de Antonio Callado, Autran Dourado, Julieta de Godoy Ladeira, Lygia Fagundes Telles, Nélida Piñon e Osman Lins (BONFIM E NÊUMANNE PINTO, 2019, p. 563).

Cabe, por fim, assinalar o alto grau de realização do ensaísmo literário a que chega o autor, com "Os braços de dona Severina", em que frequentemente o crítico trai o poeta: as "meras donas de casa que vagueiam [...] num morno ambiente doméstico" são indessedentáveis; o rapazinho e a senhora do conto em tela, ao unirem-se separados pela parede da vigília, vivem sonambulicamente a realidade; dona Conceição e dona Severina sonham $o$ milagre da volúpia absoluta e perfeita; etc. etc. Trata-se de prosa ensaística da melhor qualidade, afinada em registro, apuro, crítica e criatividade com o texto que comenta.

A Machado de Assis em linha agradece a Gonçalo Ivo, pela autorização para a reprodução de "Os braços de dona Severina".

\section{$* * *$}

O tema de "Missa do galo" percorre a obra de Machado de Assis como um veio subterrâneo, e às vezes fica ostensivo como as veias azuis nos braços de dona Conceição... Essa luta contra o demônio homiziado no mais fundo do corpo e do espírito, lá onde ambos formam um núcleo íntegro e indecomponível, está presente em muitos passos de seus romances e contos. Basta o leitor rastejá-lo, e o tema sai de seu esconderijo, e tem o sabor de uma emoção repetida, de um sonho velho. Assim, há em Machado outro conto que parece completar, ou recontar a história de dona Conceição e do rapazinho Nogueira, como se fosse o irmão gêmeo de "Missa do galo". É "Uns braços". Em ambos, irrompe o conflito entre a adolescência ainda espantada de si mesma e a plenitude feminina insaciada e talvez insaciável. Tanto o moço Inácio, de "Uns braços", como o moço Menezes, de "Missa do galo", são adolescentes sozinhos, hospedados na residência de um casal sem filhos. E 
dona Severina, a mulher do solicitador Borges, fascina o adolescente com os seus braços belos e cheios, do mesmo modo como é a visão dos braços claros de dona Conceição que faz deflagrar em Menezes a consciência da carne e do pecado. No caso de "Missa do galo", o marido de dona Conceição tem uma concubina e dorme fora. Em "Uns braços", há também uma irregularidade familiar: dona Severina não é casada com o solicitador, apenas vive com ele, maritalmente. E, nota curiosa, os dois casais não têm filhos - e o amor infecundo de ambos coloca as duas senhoras (que aliás não são bonitas, apenas simpáticas) num plano de objetos amorosos destinados só ao governo doméstico e à fruição de prazeres, e excluídos da maternidade. E talvez por isso o convergir de ambas em direção aos adolescentes tem levíssima e inconfessável tinta maternal...

Os tipos são extraordinariamente semelhantes, mas o clássico incomparável conhece como ninguém a arte de conduzir o leitor a sobrelanços inéditos, solfejar-lhe músicas novas. Se em "Missa do galo "a atmosfera claroescuro tanto está no ambiente como na consciência das personagens, em "Uns braços" esse clima de meia-luz é quase exclusivamente psicológico. O conto, de maior duração, com a fabulação atravessando alguns dias e noites, irradiase na área do lusco-fusco dos sentimentos e emoções. Nessa terrível história de um encontro que é desencontro, um rapazinho de quinze anos apaixona-se por dona Severina, senhora de belos braços e "vinte e sete anos floridos e sólidos". É um amor sorrelfo, que não ousa manifestar-se e se contenta com espiar a furto o seu objeto. Por sua vez, dona Severina não é indiferente ao rapazinho. E se, no fim da história, cobre os braços com um xale, o certo é que não cobre a realidade; não cobre os nossos olhos de leitor, subitamente arregalados diante desse mundo do mal e do pecado que aflora em tantos personagens machadianos, quando elas de repente despertam para si mesmas, sejam loucos, marginais ou alucinados, ou meras donas de casa que vagueiam indessedentáveis num morno ambiente doméstico.

Mas voltemos ao tempo em que dona Severina usava os braços nus, meio palmo abaixo dos ombros. Ela percebe que é amada e temida. Sonha certa noite com ele - e Machado não nos diz qual foi a matéria desse sonho, o que não deixa de ser uma maneira de dizê-lo, já que o acidente noturno tivera o mérito de revelar a dona Severina a natureza dos vínculos que, além das convenções, do temor e do recato, a ligariam ao jovem escrevente. Além do mais, sonhos são coisas secretas. "Que não possamos ver os sonhos uns dos outros!" deplora o narrador, que linhas antes admitia que, no sonho de dona Severina, o rapazinho era uma "tentação diabólica". E naquele domingo em 
que a própria paisagem parecia sonhar e devanear, romper as comportas de seu recato e entregar-se a uma volúpia secreta (tanto assim que as gaivotas faziam grandes giros no ar), dona Severina se detém diante do rapazinho que sonha, deitado numa rede, contempla-o dormindo, chega a considerá-lo uma criança... e o beija na boca. E essa história, esse drama de duas paixões contidas e inconfessáveis, encerra-se numa convergência de mal-entendidos. Quando dona Severina beijou o rapazinho adormecido, este sonhava que a estava beijando: "Aqui o sonho coincidiu com a realidade, e as mesmas bocas uniramse na imaginação e fora dela". E os mal-entendidos continuam a vida inteira. No dia seguinte, dona Severina cobre os braços com um xale. Dias depois, Inácio é mandado embora pelo solicitador, nem sequer logra despedir-se de dona Severina, sai "sem entender nada", como o seu irmão físico e espiritual de "Missa no galo" também não entendeu a conversação mantida com dona Conceição. E, durante a vida inteira, guardando em si mesmo o "sabor do sonho", não alcança encontrar em outros amores nenhuma sensação comparável à daquela tarde de domingo na rua da Lapa, quando contava apenas quinze anos. "Ele mesmo exclama às vezes, sem saber que se engana: E foi um sonho! Um simples sonho!".

O trágico desencontro dessa história decorre precisamente do encontro do sonho com a realidade, de fusão instantânea desses dois elementos que a tradição vital alcunha de antagônicos. Machado de Assis irroga a cada um dos comparsas, tanto à dona dos braços como ao dono do buço, pesada taxa de ilusão. E embora sonho e realidade tenham coincidido, na verdade não se encontram. Pois a vida não é sonho: se, neste, tanto dona Severina como o rapazinho se unem e se amam, a parede da vigília os separa. E, como ambos só se realizam, só se tornam reais no sonho, vivem sonambulicamente a realidade.

Ambas as histórias transgridem o esquema realista em que tanto se tem forcejado por situar Machado de Assis e penetram numa paragem suprarreal, uma terra de ninguém onde a realidade e o sonho se fundem e se repelem. E a circunstância de o tema ter suscitado dois dos mais extraordinários contos do nosso clássico está a indicar tratar-se de verdadeiro leitmotiv, cioso de seu predomínio e pronto a reclamar glosas e versões. E como não admitir que as raízes desses episódios aparentados, desse encontro ou desencontro de um rapazinho com uma senhora, estejam na própria experiência vivida de Machado de Assis, aliás tão censurado, pelos cavilosos amantes da experiência bruta, de ter esquivado a sua vida pessoal às suas ficções? 
Nos dois contos, na visão desses braços que eram como a primeiras terras antecipadoras de um país carnal, perpassa a "velha sonata do absoluto" da história intitulada "Trio em lá menor", outra fábula da indecisão, da busca, das almas incontentáveis à procura de alguma perfeição, seja a da criação artística, seja a da plenitude sexual. E em outras histórias de Machado, surpreendemos esse fio magnético que lhe percorre a obra - o conto "Cantiga de esponsais" narra a história de Romão Pires, o músico que procura, a vida inteira, acabar certo canto esponsalício iniciado três dias após o seu casamento. E também em "Um homem célebre" freme, embora muito trajado ao cômico, esse tema da obra ou do ato inatingíveis: Pestana, insigne compositor de polcas, passa a vida inteira tentando superar-se, criar um noturno, uma sonata, um réquiem.

O drama do espírito faminto de absoluto - tanto o absoluto da criação artística como o absoluto da integração amorosa - é um dos temas de Machado de Assis. O problema do adultério ou da traição, que lhe perseguiu a vida toda a imaginação de artista (como comprovam as maravilhosas criações de Virgília, Capitu e essa adúltera incompleta e fronteiriça que é a Sofia de Quincas Borba) está equacionado em "Uns braços" e "Missa do galo" na história dessas duas mulheres em luta entre o ser e o parecer, a convenção e o desejo, o pudor e a volúpia. E essas Penélopes da dissimulação tecem, dia e noite, a sua rede, que se destina a elas mesmas. Filhas amadas do grande lascivo, qualquer uma delas, seja a Sofia que não chegou a dar o grande passo definitivo, seja a resoluta Virgília, sabe que o relativo é a aparência - a verdade está no outro lado, no absoluto. E para lá todas se encaminham ou se sentem atraídas, como ocorre com as duas namoradas do abismo de "Missa do galo" e "Uns braços", ou as demais criações femininas que Machado de Assis põe sempre a um tiro de pistola do pecado. Como acontece com aquele marinheiro do conto "Noite de almirante", dona Conceição e dona Severina sonhavam com a "grande noite", o milagre da volúpia absoluta e perfeita, o trio em lá menor da carne.

\section{Referências:}

BONFIM, Beatriz; NÊUMANNE PINTO, José. O desafio de recriar Machado. Jornal do Brasil, Rio de Janeiro, 24 dez. 1977. Apud: GUIMARÃES, Hélio de Seixas; LEBENSZTAYN, Ieda (Orgs.). Escritor por escritor: Machado de Assis segundo seus pares. Vol. 2: 1939-2008. São Paulo: Imprensa Oficial do Estado de São Paulo, 2019. p. 561-569. 
GUIMARÃES, Hélio de Seixas; LEBENSZTAYN, Ieda (Orgs.). Escritor por escritor: Machado de Assis segundo seus pares. Vol. 2: 1939-2008. São Paulo: Imprensa Oficial do Estado de São Paulo, 2019.

IVO, Ledo. Os braços de dona Conceição. O Estado de S. Paulo, 20.07.1963, Suplemento Literário, p. 4.

Como distinguir um clássico. Tribuna da Imprensa, Rio de Janeiro, 24 fev. 1956. Apud: GUIMARÃES, Hélio de Seixas; LEBENSZTAYN, Ieda (Orgs.). Escritor por escritor: Machado de Assis segundo seus pares. Vol. 2: 1939-2008. São Paulo: Imprensa Oficial do Estado de São Paulo, 2019. p. 185-191.

SANTIAGO, Silviano. Retórica da verossimilhança. In: Uma literatura nos trópicos: ensaios sobre dependência cultural. 2.ed. Rio de Janeiro: Rocco, 2000. p. 27-46.

MARCELO DIEGO é professor adjunto de Literatura Comparada na Universidade Federal do Rio de Janeiro e membro do Grupo de Pesquisa / CNPq "Fiç̧ão de Machado de Assis: sistema poético e contexto". Ohttps://orcid.org/0000-0001-8590-5009

E-mail: marcelodiego@letras.ufrj.br 